Bangladesh Journal of Anatomy January 2011, Vol. 9 No. 1 pp 35-40

\title{
Reviewing and Updating of MBBS Curriculum 2002: Intern Doctors' Views
}

\author{
Md. Humayun Kabir Talukder ${ }^{1}$, Md. Zakir Hossian² Md. Abdul Hanif ${ }^{3}$, Nasrin Akther ${ }^{4}$, \\ Ismat Ara Perveen ${ }^{5}$
}

\begin{abstract}
This cross-sectional study was conducted to explore the views of intern doctors regarding reviewing \& updating of MBBS curriculum 2002. This study was conducted upon 257 intern doctors of different government and non government medical colleges in Bangladesh. Data were collected using self administered structured questionnaire using purposive sampling. Study revealed that the contents of the course, the teaching methods and the assessments system for the undergraduate medical students needs few improvement as majority of the intern doctors viewed those areas of the curriculum are all right and few of them opined for change. Study revealed that the formative \& summate assessments, carry on system, block posting and duration of internship should be redesigned \& rethink to make the curriculum more user friendly and effective as intern doctors have different opinions regarding these issues. Study also recommended that more extensive study is needed to get unanimous opinion from the intern doctor's of the medical colleges to review and update the MBBS curriculum 2002.
\end{abstract}

Key words: Review, Update, MBBS Curriculum

\section{Introduction}

Curriculum is the blue print that entails the goal of any educational activities and endeavor to achieve the goal. Curriculum in fact is an organised plan of course outlines, along with the objectives and learning experiences to be used for achievement of these activities. Curriculum refers to a series of planned activities that are intended to bring about specific learning outcomes. Curriculum development is a specialized task which requires systematic thinking about the objectives to be achieved, learning experiences to be provided, evaluation of changes brought out by the curricular activities. The word curriculum has it's root in the Latin word for track or racecourse. From there it came to mean course of study. Today the definition is much wider and includes all the planned learning experiences of a school or educational institution ${ }^{1}$. Curriculum then has to do with determining the purpose and values of the learning, analysing the needs and nature of

1. Associate Professor, (CME), Mohakhali, Dhaka,

2. Register, SDC, Dhaka.

3. Assistant Professor, DMC,

4. Assistant Professor, SSMC,

5. MPH Student, HE Dept, NIPSOM

Correspondence: Md. Humayun Kabir Talukder the learners, deciding on the outcomes or learning objectives, selecting the content, the subject matter that will support achieving the outcomes, deciding on the activities, the methods and media for teaching/training and learning, planning how assessment will be done, planning how the overall effectiveness of the delivery of the curriculum will be evaluated ${ }^{2}$. Curriculum development is a comprehensive term that includes the processes of curriculum design, implementation and evaluation. Curriculum design refers to the specific processes involved in defining the content of what should be learned and how it should be organized ${ }^{3}$.

The primary focus of a curriculum is on what is to be taught and when, leaving to the teaching profession decisions as to how this should be done. The curriculum should be open to critique, and should be able to be readily transformed into practice. The curriculum must be responsive to changing values and expectations in education if it is to remain useful ${ }^{4}$. For successful implementation, educators need to be mindful of the organizational and practical considerations associated with curriculum development. For instance, one of the first obstacles that curriculum developers will 
encounter is resistance to change. Resistance may result from a number of reasons, including inertia, lack of evidence for educational efficacy, prohibitive cost and logistics of implementing change, and the lack of personnel for implementation. Furthermore, curriculum development must also include a process of continuous program evaluation and as well as a succession plan for sustainability when the developers of the original curriculum design move on ${ }^{1}$.

The MBBS curriculum 2002 has been introduced in undergraduate medical course of Bangladesh since 2003. It divided the long 5 years course into three parts by first, second and third professional examinations. The students have to face a lot of formative examinations in each discipline. Item examinations (covering shortest content area; e.g. 1-3 topics), card examinations (covering several items; e.g. single body area or system) and term examinations (covering several items and card; e.g. two-three body areas or systems) are three types of formative assessment are held in the medical colleges to enhance intern doctor's learning and academic activities ${ }^{5}$.

The MBBS students are being taught by lectures, tutorials, practical demonstrations and beside clinical teachings. Modern teaching aid like OHP, multimedia, models were facilitating the classes of MBBS course. A good number of teachers is also trained on modern teaching and assessment methods ${ }^{5}$.

More than 5 years have been passed by this time after introducing the MBBS curriculum 2002. There might be some areas, which should incorporate the changing needs of people of the country. It is the best time to revise the existing curriculum to find out its strength and weakness and thereby improving it. Keeping those in mind these objectives of this study was designed to get the views of intern doctor's regarding undergraduate medical curriculum of Bangladesh to find out the adequacy of contents, standard of assessments \& teaching- learning, block posting in undergraduate medical curriculum and duration of internship.

\section{Methodology:}

This cross-sectional study was conducted among the intern doctors of government and non government medical colleges of Bangladesh. Purposive sampling technique was adopted to collect data. Data was collected by using a self-administered structured questionnaire. Sample size was 257.

\section{Results:}

Table-I

Distribution of respondents by their comments about contents of different subjects MBBS curriculum 2002

\begin{tabular}{lcccccc}
\hline Name of the subjects & \multicolumn{2}{c}{ Contents to be added } & \multicolumn{2}{c}{ Contents to be reduced } & \multicolumn{3}{c}{ Contents all all right } \\
& No. & $\%$ & No. & $\%$ & No. & $\%$ \\
\hline Anatomy & 24 & 9.3 & 42 & 16.3 & 191 & 74.3 \\
Physiology & - & - & 5 & 1.9 & 252 & 98.1 \\
Biochemistry & 12 & 4.7 & 27 & 10.5 & 218 & 84.8 \\
Community Medicine & - & - & 257 & 100 & - & - \\
Pharmacology & 30 & 11.7 & 37 & 14.4 & 190 & 73.9 \\
Forensic Medicine & - & - & 136 & 52.9 & 121 & 47.1 \\
Pathology & 42 & 16.3 & 17 & 6.6 & 198 & 77 \\
Microbiology & 8 & 3.1 & - & - & 249 & 96.9 \\
Medicine & - & - & - & - & 257 & 100 \\
Surgery & 20 & 7.8 & - & - & 237 & 92.2 \\
Gynecology \& Obstetrics & - & - & - & - & 250 & 97.3 \\
\hline
\end{tabular}

Table-I has shown distribution of respondents by their comments about contents of different students MBBS curriculum 2002. It was observed that majority of intern doctors have viewed subject of it was all right and most of the respondents viewed that contents to be reduced. 
Bangladesh J. Anat. 2011; 9(1) : 35-40

Table-II

Distribution of respondents by their comments about teaching hours of different subjects of MBBS curriculum 2002

\begin{tabular}{lcccccccc}
\hline Name of the subjects & \multicolumn{2}{c}{ Hours to be added } & & \multicolumn{2}{c}{ Hours to be reduced } & & \multicolumn{2}{c}{ Hours all right } \\
\cline { 2 - 3 } & No. & $\%$ & & No. & $\%$ & & No. & $\%$ \\
\hline Anatomy & 50 & 19.5 & & 20 & 7.8 & & 187 & 72.8 \\
Physiology & 32 & 12.5 & & - & - & & 225 & 87.5 \\
Biochemistry & 25 & 9.7 & & 16 & 6.2 & & 216 & 84 \\
Community Medicine & 5 & 1.9 & & 183 & 71.2 & & 69 & 26.8 \\
Pharmacology & 20 & 7.8 & & 20 & 7.8 & & 217 & 84.4 \\
Forensic Medicine & - & - & & 137 & 53.3 & & 108 & 42 \\
Pathology & 109 & 42.4 & & - & - & & 148 & 57.6 \\
Microbiology & 45 & 17.5 & & - & - & & 212 & 82.5 \\
Medicine & 75 & 29.2 & & 10 & 3.9 & & 172 & 66.9 \\
Surgery & 130 & 50.6 & & - & - & & 127 & 49.4 \\
Gynecology \& Obstetrics & 12 & 4.7 & & 33 & 12.8 & & 212 & 82.5 \\
\hline
\end{tabular}

Table-II has shown that few of the respondents has expressed that hours to be added, many expressed to reduced and most of the respondents expressed that hours are all right.

Table-III

Distribution of respondents by their comments about item examination of MBBS curriculum 2002

\begin{tabular}{|c|c|c|c|c|c|c|}
\hline \multirow[t]{2}{*}{ Name of the subjects } & \multicolumn{2}{|c|}{$\begin{array}{l}\text { Item examination } \\
\text { to be added }\end{array}$} & \multicolumn{2}{|c|}{$\begin{array}{c}\text { Item examination to } \\
\text { be reduced }\end{array}$} & \multicolumn{2}{|c|}{$\begin{array}{c}\text { Item examination } \\
\text { all right }\end{array}$} \\
\hline & No. & $\%$ & No. & $\%$ & No. & $\%$ \\
\hline Anatomy & 21 & 8.2 & 20 & 7.8 & 216 & 84 \\
\hline Physiology & 10 & 3.9 & 5 & 1.9 & 242 & 94.2 \\
\hline Biochemistry & 20 & 7.8 & 24 & 9.3 & 213 & 82.9 \\
\hline Community Medicine & 41 & 16 & 174 & 67.7 & 30 & 11.7 \\
\hline Pharmacology & 12 & 4.7 & 35 & 13.6 & 210 & 81.7 \\
\hline Forensic Medicine & 113 & 44 & 136 & 52.9 & 8 & 3.1 \\
\hline Pathology & 16 & 6.2 & 15 & 5.8 & 226 & 84.9 \\
\hline Microbiology & 5 & 1.9 & 11 & 4.3 & 241 & 93.8 \\
\hline Medicine & 94 & 36.6 & - & - & 163 & 63.4 \\
\hline Surgery & 105 & 40.9 & - & - & 152 & 59.1 \\
\hline Gynecology \& Obstetrics & 51 & 19.8 & - & - & 206 & 80.2 \\
\hline
\end{tabular}

Table-III has shown that distribution of respondents by their comments about item examinations of MBBS curriculum 2002. Majority of intern doctors have viewed that item examinations are all right few of them replied that item examinations to be reduced and few of respondents also viewed that item examination should be added. 
Bangladesh J. Anat. 2011; 9(1) : 35-40

Table-IV

Distribution of respondents by their comments about term examination of MBBS curriculum 2002

\begin{tabular}{|c|c|c|c|c|c|c|c|c|}
\hline \multirow[t]{2}{*}{ Name of the subjects } & \multicolumn{2}{|c|}{$\begin{array}{l}\text { Terms examination } \\
\text { to be added }\end{array}$} & \multicolumn{2}{|c|}{$\begin{array}{l}\text { Terms examination } \\
\text { to be reduced }\end{array}$} & \multicolumn{2}{|c|}{$\begin{array}{l}\text { Terms examination } \\
\text { all right } \\
\end{array}$} & \multicolumn{2}{|c|}{$\begin{array}{l}\text { Terms examination } \\
\text { to be eliminated }\end{array}$} \\
\hline & No. & $\%$ & No. & $\%$ & No. & $\%$ & - & - \\
\hline Anatomy & 27 & 10.5 & 10 & 3.9 & 220 & 85.6 & - & - \\
\hline Physiology & 12 & 4.7 & - & - & 245 & 95.3 & - & - \\
\hline Biochemistry & 12 & 4.7 & 10 & 3.9 & 235 & 91.4 & - & - \\
\hline Community Medicine & 5 & 1.9 & 68 & 26.5 & 172 & 66.9 & 12 & 4.7 \\
\hline Pharmacology & - & - & - & - & 257 & 100 & - & - \\
\hline Forensic Medicine & 50 & 19.5 & - & - & 207 & 80.5 & - & - \\
\hline Pathology & 31 & 12.1 & - & - & 226 & 87.9 & - & - \\
\hline Microbiology & 20 & 7.8 & - & - & 237 & 92.2 & - & - \\
\hline Medicine & 80 & 31.1 & 12 & 4.7 & 155 & 60.3 & 10 & 3.9 \\
\hline Surgery & 88 & 34.2 & 12 & 4.7 & 147 & 57.2 & 10 & 3.9 \\
\hline Gynecology \& Obstetrics & 14 & 5.4 & 12 & 4.7 & 221 & 86 & 10 & 3.9 \\
\hline
\end{tabular}

Table-IV has shown that distribution of respondents by their comments about term examinations of MBBS curriculum 2002. Majority of intern doctors have viewed that term examinations are all right few of them replied that term examinations to be reduced and few of respondents also viewed that term examination should be added.

Table-V

Distribution of respondents by their comments about number of formative assessment, written assessment MCQ, SAQ, OSPE/OSCE, SOE, block posting and internship in the MBBS course.

\begin{tabular}{lccccccc}
\hline $\begin{array}{l}\text { Comments formative } \\
\text { assessment, written } \\
\text { assessment MCQ, }\end{array}$ & $\begin{array}{c}\text { Formative } \\
\text { assessment }\end{array}$ & MCQ & SAQ & OSPE/OSCE & SOE & $\begin{array}{c}\text { Block } \\
\text { Posting }\end{array}$ & Internship \\
$\begin{array}{l}\text { SAQ, OSPE/OSCE, } \\
\text { SOE, block posting } \\
\text { and internship }\end{array}$ & & & & & & & \\
\hline All right & $30(11.7)$ & 214 & $224(87.2)$ & $99(38.5)$ & $127(49.4)$ & $73(28.4)$ & $91(35.4)$ \\
To be redesigned & $179(69.6)$ & $43(16.7)$ & $33(12.8)$ & $158(61.7)$ & $130(50.6) 166(64.6)$ & $166(64.6)$ \\
To be increased & - & - & - & - & - & - & - \\
To be reduced & $32(12.5)$ & - & - & - & - & - & - \\
To be eliminated & $16(6.2)$ & - & - & - & - & $18(7)$ & - \\
\hline
\end{tabular}

Table- $V$ shows that most of the respondents viewed to redesign formative assessment, OSPE/OSCE, SOE, block posting \& internship though few of the respondents viewed as all right. Most of the respondents expressed their views about MCQ \& SAQ as all right. 
Bangladesh J. Anat. 2011; 9(1) : 35-40

Table-VI

Distribution of respondents by their comments about number of professional examination per year and total number of professional examinations in MBBS course.

\begin{tabular}{lcc}
\hline Comments about the number of professional examination per year. & Number & $\%$ \\
\hline Two Professional examination per year (six months interval) & 15 & 5.8 \\
Three Professional examination per year (four months interval) & 242 & 94.2 \\
Total & 257 & 100 \\
Comments about total number of professional examinations in MBBS course. & & \\
Total three in number & 117 & 45.5 \\
Total four in number & 138 & 53.6 \\
Total five in number & - & - \\
\hline Total & 257 & 100 \\
\hline
\end{tabular}

Table VI shows that most of the respondents viewed that three professional examinations should be per year and more respondents expressed their views in favour of total four professional examinations in MBBS course

Table-VII

Distribution of respondents by their comments about when the students should attend $3^{\text {rd }}$ year classes

\begin{tabular}{lcc}
\hline $\begin{array}{l}\text { Comments about the time } \\
\text { when students should attend } \\
3^{\text {rd }} \text { year classes }\end{array}$ & Number & $\%$ \\
\hline $\begin{array}{l}\text { After passing } 1^{\text {st }} \text { professional } \\
\text { examination }\end{array}$ & 27 & 10.5 \\
$\begin{array}{l}\text { After appearing } 1^{\text {st }} \text { professional } \\
\text { examination }\end{array}$ & 230 & 89.5 \\
\hline
\end{tabular}

Table-VII shows that most of the students expressed their views that students should attend $3^{\text {rd }}$ year classes after appearing the $1^{\text {st }}$ professional examination though few expressed that students should attend $3^{\text {rd }}$ year classes after passing $1^{\text {st }}$ professional examination.

\section{Discussion}

To make representative views intern doctors of different govt. \& non govt. medical colleges were involved in this study. The contents and teaching hours of different subjects in MBBS curriculum 2002 are all right except two subjects (Community Medicine \& Forensic Medicine). Few of the respondents viewed to viewed to reduced the contents of all subjects as majority of intern doctors were partially satisfied with the present content and teaching hour. Ahamed found that the major subjects are overloaded with content in relation to the time allocated for the subjects ${ }^{6}$. Alam conducted study on 550 doctors in Upozela Health Complex and found more than $80 \%$ doctors were satisfied with the knowledge and skills they acquired during graduation, they also recommend 129 health problems which should be included in undergraduate medical education?

It can assumed that item and term examinations of MBBS course were optimum probably, as majority of the intern doctors viewed those as all right and few of them viewed that it should be decreased. On the other hand, regarding formative assessment majority of intern doctors viewed it as all right, few of them viewed that it should be eliminated or redesigned. Khan found that students of $1^{\text {st }}$ and $2^{\text {nd }}$ phase mentioned that the formative assessments as a good system and of them were satisfied with the assessment system as a whole ${ }^{8}$. Alam and Asaduzaman ${ }^{10}$ have shown that majority of students and students of the medical colleges agreed that they are benefited from that formative assessments ${ }^{9}$.

Regarding number of professional examination per year nearly almost intern doctors viewed as 3 
professional examinations per year. But about the total number of professional examination in MBBS course intern doctors divided in to nearly equally two half, which indicates that more efforts is required to decide upon what should be the number of professional examinations in MBBS course. It will be better if the total number of professional examination in MBBS course is 4 in numbers, as majority of the intern doctors viewed this. Ahamed found that the more than $60 \%$ pre and para clinical students viewed that the number of professional examination in MBBS course should be four in numbers ${ }^{6}$. Majority intern doctors opinion is that students should be allowed to attend $3^{\text {rd }}$ year classes after appearing ${ }^{\text {st }}$ professional examination.

Regarding block posting in the clinical classes, OSPE/OSCE, SOE in assessment procedure and internship after the MBBS course most of the intern doctors viewed that block posting \& internship to be redesigned. So, to decide upon block posting and duration internship opinion of large number of intern doctors should be evaluated.

\section{Recommendations:}

Study recommended that the contents and teaching hour of different subjects, item and term examinations of MBBS course needs to redesign $\&$ reduce. Study also recommended that the formative assessments, OSPE/OSCE, SOE, block posting and duration of internship to be redesigned extensively. It was also recommended that students should attend $3^{\text {rd }}$ year classes after passing $1^{\text {st }}$ professional examination, total number professional examinations should be four in MBBS course with the provision of three professional examinations per year with four months interval..

\section{References:}

1. Prideaux D. Clinical review: $A B C$ of learning and teaching in medicine curriculum design, B M J 2003;326:268-70.
2. Nkomo M. The National Qualifications Framework and Curriculum Development, South African Qualifications Authority; 2000 May. 7-9.

3. WongAK. Curriculum development in anesthesia: basic theoretical principles. Canadian Journal of Anesthesia 2006 (53) 950-60.

4. Curriculum Development, Canadian Encyclopedia, www.thecanadianencyclopedia. com/index.cfm?

5. Curriculum for under-graduate medical education of Bangladesh, 2002. Centre for Medical Education, Dhaka.

6. Ahamed AU. Perception of the preclinical and para-clinical on the Undergraduate Medical Education Curriculum, 2002, focused on practical and oral assessment in the professional assessment. Centre for Mecal Education, Dhaka

7. Khan TF. Implementation of new assessment system in Undergraduate Medical Education of Bangladesh.[Thesis] Centre for Medical Education, July 2008. 56-57.

8. Alam KK. Views of government doctors working in Primery Health Care level for assessing the needs for curriculum development of undergraduate medical education of Bangladesh. Centre for Medical Education, 2008.

9. Alam KK, Formative Assessment in undergraduate medical education in medical colleges of Bangladesh: Situation Analysis, [Thesis] Centre for Medical Education, 2008 64-70.

10. Asaduzaman AKM. Practice of formative assessment in $2^{\text {nd }}$ professional MBBS subjects: opinion of $4^{\text {th }}$ year Medical Intern doctor's, Centre for Medical Education, Dhaka. 2008. 